\title{
Metodologia participativa para elaboração de planos municipais de cultura: uma experiência aplicada ${ }^{1}$

\author{
Metodología participativa para la elaboración \\ de planes municipales de cultura: una experiencia aplicada
}

\author{
Participatory methodology for the elaboration \\ of municipal culture plans: an applied experience
}

\author{
Luiz Augusto Fernandes Rodrigues ${ }^{2}$ \\ Marcelo Silveira Correia ${ }^{3}$
}

\section{Palavras-chave: \\ Plano municipal de cultura \\ Gestão compartilhada \\ Metodologia \\ participativa para \\ planejamento cultural}

\section{Resumo:}

Apresentação de metodologia participativa e integrada utilizada na elaboração de planos municipais de cultura. O trabalho relata experiência desenvolvida no estado do Rio de Janeiro, fruto de parceria técnica entre o Laboratório de Ações Culturais da Universidade Federal Fluminense (LABAC-UFF) e a Secretaria de Estado de Cultura do Rio de Janeiro (SEC-RJ), ação decorrente do programa PADEC - edição 2015. O artigo aponta parte do processo, breves relatos e reflexões sobre o tema.

1 Texto recebido em 07/10/2019 e aceito para publicação em 23/10/2019.

2 Luiz Augusto Fernandes Rodrigues. Doutor em História, pela UFF. Professor Titular do Departamento de Arte da Universidade Federal Fluminense, Brasil. Contato: luizaugustorodrigues@id.uff.br - https://orcid.org/0000-0003-0583-9641

3 Marcelo Silveira Correia. Mestre em Cultura e Territorialidades pela Universidade Federal Fluminense, Brasil. Contato: marcelonetcorreia@hotmail.com 


\section{Resumen:}

Presentación de metodología participativa e integrada utilizada en la elaboración de planes municipales de cultura. La experiencia de los informes de trabajo se desarrolló en el estado de Río de Janeiro, resultado de una asociación técnica entre el Laboratorio de Acciones Culturales de la Universidad Federal Fluminense (LABACUFF) y la Secretaría de Estado de Cultura de Río de Janeiro (SECRJ), una acción resultante del Programa PADEC - edición 2015. El artículo señala parte del proceso, breves informes y reflexiones sobre el tema.

\section{Palabras clave:}

Plan municipal de cultura

Gestión compartida

Metodologia

participativa para la planificación cultural

\section{Keywords:}

Municipal culture plan

Shared management

Participatory methodology for cultural planning

\section{Abstract:}

This article presents a participatory and integrated methodology used in the elaboration of municipal plans of culture. The work reports experience developed in the state of Rio de Janeiro, a result of a technical partnership between the Laboratory of Cultural Actions of the Federal Fluminense University (LABAC-UFF) and the State Secretariat of Culture of Rio de Janeiro (SEC-RJ), an action resulting of the PADEC Program - 2015 edition. The article points out part of the process, brief reports and reflections on the subject. 


\section{Metodologia participativa para elaboração de planos municipais de cultura: uma experiência aplicada}

\section{Apresentação}

Trazer a experiência do processo participativo de construção de planos municipais de cultura é, além de apresentar a proposta metodológica, assumir um lugar de fala privilegiado, pois o que aqui é apresentado foi dito, pensado e construído através de relações dialógicas não subalternizadas. Poderiam alguns argumentar: mas a Universidade é um lugar de hegemonias. Sim, é fato, mas a metodologia proposta buscou minimizar tal impacto... Falaremos, aqui, de uma proposta que foi norteadora e não impositiva; não se tratou de uma consultoria para aplicação de metodologia fechada, pronta, e sim de uma possibilidade de aplicação que - entendemos - permitiria aos municípios a construção de processos participativos, democráticos e abrangentes para a formulação de suas políticas públicas de cultura.

A formulação desta proposta metodológica partiu da experiência junto ao bacharelado em Produção Cultural da Universidade Federal Fluminense, e foi formalizada através de parceria entre o Laboratório de Ações Culturais (LABAC-UFF) e a Secretaria de Estado de Cultura do Rio de Janeiro (SEC-RJ) para ação junto a municípios fluminenses através do Programa de Apoio ao Desenvolvimento Cultural dos Municípios (PADEC) - Edição 2015. Este Programa incluiu processo de formação de gestores culturais, dotação de infraestrutura para equipamentos culturais municipais e ações dinamizadoras para a elaboração de planos de cultura (experiência que será aqui relatada). Trinta e quatro (34) municípios fluminenses aderiram à ação de dinamização assinando Termo de Compromisso com a Secretaria de Estado de Cultura do RJ, de modo a receber apoio para construção e implementação do Plano Municipal de Cultura (PMC), através da presença de um agente dinamizador voltado a integrar poder público e sociedade civil. Foram ao todo selecionados oito "Dinamizadores", que atenderiam a mais de um terço de municípios do estado que aderiram ao Programa. A ação de dinamização compreendeu, de maneira geral, a seguinte metodologia: 1. apresentar aos munícipes a ação de elaboração do PMC, através de procedimentos compartilhados entre agentes do governo e da sociedade civil; 2 . criar um grupo de trabalho (GT) misto com a finalidade de compilar documentos e diretrizes, levantar mapeamentos e informações sobre os processos culturais locais etc.; 3 . propor e discutir junto ao GT a aplicação de metodologia específica (que será detalhada mais a frente) para a definição de diretrizes e ações norteadoras do PMC; 4. apresentação à sociedade civil como um todo, assim como a agentes dos poderes executivo e legislativo os resultados preliminares, possibilitando/potencializando a futura aprovação do PMC como lei. Cabe destacar que o processo de dinamização buscou estimular que outras peças do Sistema Municipal de Cultura (SMC) fossem viabilizadas, em especial: a) implantação do conselho de política cultural (no caso de municípios que ainda não o tivesse), e b) criação de um sistema público de financiamento da cultura, com a implementação especialmente de um fundo municipal de cultura voltado a - sobretudo através de editais públicos - viabilizar ações constantes do PMC. Buscou-se assim, fortalecer a gestão pública de cultura sob parâmetros amplos, democráticos e participativos.

Este artigo se estrutura, inicialmente, de modo a discutir a noção de gestão cultural. Segue relatando parte das políticas públicas de cultura inauguradas com a gestão do Ministro Gilberto Gil que foram voltadas à fortalecer ações sistêmicas e participativas. $\mathrm{O}$ artigo segue apresentan- 
do detalhadamente e de modo exemplificado a metodologia sugerida para a construção de planos municipais de cultura.

\section{Gestão cultural: conceito norteador da ação}

Comecemos por discutir algumas noções sobre gestão cultural. Por gestão cultural adotou-se a proposição de Rodrigues e Castro (2017, p. 46) que a entendem como "campo próprio, articulando o conceito com noções como mediação e acesso aos bens culturais e de fomento às práticas culturais dos territórios". Os autores já haviam proposto anteriormente (2015) uma forma particular de lidar com o universo da cultura; deixando a noção de gestão como universo administrativo. Assim, propõem

[...] retirar a ênfase do termo gestão, o que tenderia a ter a cultura vinculada a ações gerenciais e ao cumprimento de metas e objetivos que nem sempre são norteados por reais parâmetros de efetividade, e colocar mais foco no termo cultura, entendido aqui em suas dimensões estéticas sob bases que ultrapassam os códigos simbólicos mais hegemônicos, dimensões cidadãs construídas a partir do direito universal de ampla participação dos sujeitos e grupos na criação, fruição e planejamento de processos no campo da cultura e da arte, dimensões econômicas entendidas aqui muito mais pela ampliação do acesso aos bens da cultura humana do que às lógicas de produtividade e geração obrigatória de renda ou lucro.

O que nos parece mais adequado é que a utilização do termo gestão cultural pressuponha a gestão de processos e mediações no campo cultural, com suas diferenças e negociações imanentes. Assim, os gestores culturais, assim puramente nominados, seriam aqueles sujeitos norteados pelos firmes propósitos da Gestão Cultural.
Os demais seriam gestores institucionais, gestores governamentais de políticas culturais, gestores ou produtores de projetos culturais, produtores executivos (de projetos, de espaços...) etc. (RODRIGUES; CASTRO, 2015, $\mathrm{s} / \mathrm{p}$, grifos do documento original)

Por outro lado, diferentes autores vêm apontando a necessidade de se entender política cultural como esfera que ultrapassa a dimensão governamental. Dentre outros, destacamos a formulação inaugural de García Canclini $\left(1987^{4}\right.$, p. 26) que concebe as políticas culturais como "conjunto de intervenciones realizadas por el estado, las instituiciones civiles y los grupos comunitarios organizados a fin de orientar el desarrollo simbólico, satisfacer las necesidades culturales de la población y obtener consenso para un tipo de orden o de transformación social".

Sob tais pressupostos, busca-se fortalecer as dimensões participativa e cidadã, e inseri-las nas diversas possibilidades dos circuitos culturais e suas políticas.

Brunner (1985a) designa cultura como um conjunto de circuitos nos quais intervêm os agentes produtores (artistas e criadores), os meios de produção (entendidos pelas tecnologias disponíveis e utilizadas, os recursos econômicos e a propriedade dos meios de produção), formas comunicativas (divulgação dos bens culturais, agentes distribuidores e dispositivos de troca), públicos e instâncias organizativas (estas podendo ser ligadas ao setor público, privado e/ou comunitário); nas instâncias organizativas se encontram as agências financia-

$4 \quad$ Este texto, assim como outros do autor, ganhou uma publicação recente em português, que integra o livro Política cultural: conceito, trajetória e reflexões ( $N$. García Canclini), organizado por Renata Rocha e Juan Brizuela e editado pela EDUFBA em 2019. 
doras, produtores privados, órgãos públicos de controle e estímulo, escolas de formação etc. Ou seja, as reflexões de Brunner sobre os circuitos nos remetem ao sistema de produção cultural e suas etapas: produção/criação, distribuição, troca, uso/consumo (ou reconhecimento). (LIMA; RODRIGUES, 2014, p. 853)

Procura-se reforçar a necessidade de canais efetivos de participação como estratégia fundamental para se instituir políticas. Como apontado por Rodrigues (2009, pp. 83-91)

Participação e esfera pública são ideias inseparáveis. Fazem parte da própria concepção de política. É necessário refletir sobre esse termo. [...] Nosso desafio, hoje, é alcançar formas que, para além de preservar, democratizar e incentivar modos e práticas culturais diversificados, criem estratégias que reforcem o exercício público e político dos diversos atores sociais, a fim de que todos e cada um possam ser protagonistas de si mesmos. [...] Creio, firmemente, que nosso desafio é conseguir constituir redes diversificadas de agentes sociais. O próprio conceito de rede reforça a possibilidade de êxito de qualquer proposta: rede que se estabelece a partir do comprometimento e do envolvimento das mais diversas esferas. É esse trabalho de "varejo" que pode efetivamente construir novas possibilidades de caminhos conjuntos. Uma ação que se desdobra nos usuários mais diretos e neles com suas redes mais particularizadas, que, pouco a pouco, podem se agregar aos "fios" anteriores. Dessa nova trama serão irradiados novos fios (que a ela se unem) e assim sucessivamente, tal qual nós de uma rede que se vai tecendo. [...] O Brasil vivenciou durante muito tempo a falência de políticas sociais públicas inclusivas, ficando sob a ação sociocultural de organizações não governamentais. São mais de cem mil ONGs e centenas de milhares de voluntários. Caminho que, sozinho, também não resolve. $O$ aterrorizante "abismo social" que marca a sociedade brasileira tem mobilizado cada vez mais ações de segmentos os mais diversificados. Quando nos detemos nos índices de pobreza e de ausência de condições mínimas de vida, vemos um quadro no mínimo estarrecedor. Em face de tanta carência, não podemos pensar isoladamente na arte, na cultura, na educação, na sociabilidade, na exclusão social ou em outros tantos "nas". Não podemos implementar ações isoladas. Trata-se de prover e garantir a própria cidadania. Cultura e cidadania seriam como que palavras de ordem.

\section{Políticas de cultura e participação no Brasil hoje...}

Ao observar o Prefácio para o livro de Ana Clarissa Fernandes de Souza (2015), constata-se a necessidade de se aprofundar os estudos das políticas culturais, destacando o foco analítico da autora ao refletir sobre a implementação de políticas culturais de cunho mais participativo, como aquelas propostas pelo Sistema Nacional de Cultura e pelos sistemas estaduais e municipais dele resultantes (ações ainda em processo de institucionalização e sistematização.

A proposição de políticas para a cultura e para sua melhor organização e fomento vem assumindo maior consistência e centralidade, e estamos vivendo um momento histórico, no qual podem ser constatadas algumas tentativas de ultrapassar a tônica mercadológica das políticas culturais dos anos 90 - "cultura é um bom negócio" - em prol de novas formas de construção de políticas para a cultura em formatos mais democratizantes e socialmente compartilhados. (RODRIGUES apud SOUZA, 2015, p. VII) 
O Sistema Nacional de Cultura (SNC) foi incluído, em 2012, na Constituição Federal de 1988 como Artigo 216-A. Posteriormente, passou-se a contar com o Sistema Estadual de Cultura do Estado do Rio de Janeiro (SIEC) - Lei 7035, sancionada em 7 de julho de 2015. Cabe agora aos municípios criarem suas leis municipais de cultura (alguns municípios do RJ já criaram suas leis).

Sistemas municipais integram, minimamente, o de nominado CPF da Cultura, isto é: CONSELHO - PLANO - FUNDO. Institucionalidades geridas por órgão gestor próprio do município (Secretaria ou Fundação de Cultura) em parceria e controle pela Sociedade Civil.

Buscando implementar o seu sistema de cultura, os municípios devem realizar Conferências de Cultura, momento no qual a sociedade como um todo discute a aponta diretrizes para a política cultural local. Momento propício, também, para a eleição de representantes da sociedade e da vida cultural do município para comporem o Conselho Municipal de Política Cultural (ou nome similar). Conselho e demais munícipes terão a incumbência também de participar da construção e acompanhamento do Plano Municipal de Cultura, que estabelecerá metas e diretrizes do curto ao longo prazo, prevendo ações de até 10 anos para sua devida implantação. Para garantir a implantação do Plano são necessários recursos financeiros, mobilizados através do Fundo Municipal de Cultura.

Complementarmente, os municípios devem se aliar a outras duas demandas do Sistema Nacional de Cultura: programa de formação na área cultural; sistema de indicadores e informações culturais.

O Plano Nacional de Cultura (PNC) foi incluído na Constituição Federal em 2010, através do Art. 215. Foi regulamen- tado e detalhado na lei $n^{\circ} 12.343 / 2010$ (estruturada em 5 Capítulos e Anexo com as Diretrizes, estratégias e ações. Contem 53 Metas. Já o Plano Estadual de Cultura do RJ é peça integrante da Lei do Sistema Estadual (Capítulo 2 desta lei), também integrado por Anexo estruturado em 6 eixos temáticos, que contemplam 15 diretrizes e um total de 66 estratégias. São documentos importantes e que devem dialogar com o plano municipal.

\section{A criação dos planos municipais de cultura: proposta metodológica...}

Os relatos a seguir apresentam a proposta metodológica desenvolvida para fomentar junto aos municípios fluminenses a implementação e construção de seus planos de cultura. Os planos são garantia de condução continuada das políticas e programas culturais locais, e permitem ao município acompanhar a realização de suas metas, e avaliá-las.

A proposição partiu do entendimento de que a metodologia elencada a seguir ajudaria ao município estabelecer demandas diversificadas e inclusivas, pensá-las em perspectivas temporais, propor maneiras de avaliação (quantitativa e qualitativa), buscar identificar parcerias (governamentais, institucionais e societárias), sobretudo dadas as dificuldades operacionais e financeiras de boa parte dos aparatos institucionais da política cultural municipal.

A proposta é que o PLANO trace metas e diretrizes que atendam à cadeia produtiva da cultura como um todo. Com isso, pode-se pensar sob a lógica de um circuito ou sistema de produção:

\footnotetext{
. CRIAÇÃO / PRODUÇÃO;

. DIVULGAÇÃO / DISTRIBUIÇÃO;

. ACESSO AOS BENS E SERVIÇOS;

. FRUIÇÃO, USO E CONSUMO DOS BENS E SERVIÇOS CULTURAIS.
} 
Por exemplo, um CD musical para existir e ser apreciado precisa percorrer um conjunto de etapas:

. Precisa que os artistas componham as canções e que o disco seja produzido;

. Precisa estar disponível das lojas, ou em sites (assim por diante);

- Precisa estar acessível aos ouvintes, seja através da compra ou de acesso gratuito ou subsidiado;

- Precisa que as pessoas efetivamente se apropriem daquele bem; não basta comprar o CD e deixá-lo na estante. É preciso que ele seja fruído e apreciado.

Para auxiliar na construção do PLANO MUNICIPAL, propõe-se metodologia estruturada em quatro eixos, conforme a seguir.

\section{EIXO 1: FRUIÇÃO E PRODUÇÃO} ARTÍSTICA E CULTURAL

(fomento às artes visuais, artes cênicas, música, audiovisual e literatura);

\section{EIXO 2: MANIFESTAÇÕES CULTURAIS POPULARES}

(fomento ao artesanato, reforço e/ou implementação de práticas e festejos populares -como Folias, Blocos de carnaval etc.);

EIXO 3: TURISMO CULTURAL, PATRIMÔNIO AMBIENTAL E CONSTRUÍDO (valorização, recuperação e preservação dos ambientes afetivos locais e ações de atração turística a partir dos patrimônios e da memória);

EIXO 4: SOCIABILIDADE, COMUNICAÇÃO, PARTICIPAÇÃO SOCIAL E DESENVOLVIMENTO SÓCIO-ECONÔMICO SUSTENTÁVEL

(ações que reforcem a coesão social e a interação entre as pessoas; formas de compartilhamento da gestão pública de cultura - por ex.: Conselhos, Conferências, Fundos de financiamento; ações de geração de renda e emprego e de circulação das produções culturais; etc.).

As propostas lançadas devem identificar os agentes protagonistas potenciais (executores e parceiros) de cada ação e planejá-las segundo perspectivas de curto, médio ou longo prazo. Como critério genérico para as perspectivas temporais propôs-se as seguintes temporalidades norteadoras para as ações: a) de curto prazo, 1 a 2 anos; b) de médio prazo, 3 a 6 anos; c) de longo prazo, 7 a 10 anos.

Outrossim, apontou-se a necessidade de se prever formas de Avaliação sobre a cumprimento das metas. propostas.

A seguir, sugestão de quadro de

\begin{tabular}{|c|c|c|c|c|c|}
\hline \multicolumn{6}{|c|}{$\begin{array}{l}\text { EIXO: } \\
\text { DESAFIO: }\end{array}$} \\
\hline $\begin{array}{l}\text { Ações } \\
\text { propostas }\end{array}$ & $\begin{array}{l}\text { Tempo de } \\
\text { implementação } \\
\text { (curto, médio } \\
\text { ou longo prazo) }\end{array}$ & $\begin{array}{l}\text { Ciclo de } \\
\text { frequência } \\
\text { (único, anual, } \\
\text { bienal, bianual } \\
\text { etc.) }\end{array}$ & $\begin{array}{l}\text { Possíveis } \\
\text { parceiros }\end{array}$ & $\begin{array}{l}\text { Resultados } \\
\text { Esperados }\end{array}$ & $\begin{array}{l}\text { Formas de } \\
\text { AVALIAÇÃo } \\
\text { dos resultados }\end{array}$ \\
\hline $1.1 \ldots$ & & & & & \\
\hline
\end{tabular}




\section{Ação PADEC - edição 2015 junto a mu- nicípios do estado do Rio de Janeiro...}

PADEC é um Programa de Apoio ao Desenvolvimento Cultural dos Municípios, desenvolvido a partir de parceria entre a Secretaria de Estado de Cultura do Rio de Janeiro com o Ministério da Cultura. Assenta-se em quatro linhas de apoio: 1) Qualificação da gestão pública da cultura; 2) Preservação do patrimônio material; 3) Fortalecimento da identidade cultural local; 4) Melhoria da infraestrutura para a cultura local. Para a edição de 2015, o PADEC-RJ ofereceu três linhas de ação aos municípios do estado:

a) Curso de Formação de Gestores Públicos e Agentes Culturais (em sua segunda edição);

b) Implantação e modernização de espaços culturais;

c) Aplicação de Metodologia de Apoio para a organização dos Sistemas Municipais de Cultura.

Esta terceira linha de ação foi construída com apoio técnico do Laboratório de Ações Culturais da UFF. Incluiu a proposição da metodologia supracitada, estimulada junto aos municípios que conveniaram a ação PADEC, através de processo denominado de Dinamização Ação de Apoio aos Sistemas Municipais de Cultura. Não se tratava de consultoria para confecção de planos municipais, e sim de buscar acionar e estimular o desenvolvimento dos planos de forma compartilhada entre executivo municipal da área da Cultura e representantes da sociedade civil.

Como exemplificação (bem sucinta e esquemática) sobre a possibilidade de se pensar o planejamento cultural local a partir das bases propostas, tomamos - não como forma modelar - possível exemplo para cada eixo. Importante ressaltar que as diretrizes traçadas em conferências municipais realizadas são a fonte principal para o processo, que deve retornar para ampla apreciação por parte da sociedade civil como um todo.

\section{Exemplo exploratório 1:}

Segundo levantamentos para o município de TANGUÁ, pela Munic $2006^{5}$ o município não possuía teatro e já desenvolvera oficinas de formação teatral (apontando para uma vocação ou desejo local).

Pelo site Mapa de Cultura ${ }^{6}$, observa-se a permanência da inexistência de teatro, mas também que o município conta com anfiteatro ao ar livre (Espaço Cultural Observatório de Talentos).

Considerando como DESAFIO, dentro do eixo FRUIÇÃO E PRODUÇÃO ARTíSTICA E CULTURAL, o fomento às artes cênicas, podemos então buscar elencar um conjunto de ações para enfrentar tal Desafio, levando-se em conta as fases do circuito ou sistema de produção cultural:

Criação / Produção:

a.1) desenvolvimento de oficinas de teatro, de dança, de cenotécnica, de construção de cenários e figurinos etc.;

a.2) workshops com grupos artísticos locais e externos;

a.3) residências artísticas.

Distribuição e divulgação:

b.1) concursos (esquetes, dramaturgia etc.) e festivais;

b.2) editais para circulação de espetáculos;

$5 \quad$ MUNIC é um levantamento pormenorizado de informações sobre a estrutura, a dinâmica e o funcionamento das instituições públicas municipais feito pelo Instituto Brasileiro de Geografia e Estatística (IBGE). Em 2005, o Ministério da Cultura encomendou ao IBGE tal suplemento sobre a organização das bases culturais dos municípios brasileiros, cujos resultados ficaram conhecidos como Munic 2006.

6 Plataforma estadual de informações básicas sobre os 92 municípios do estado do Rio de Janeiro. Disponível em: http://mapadecultura.rj.gov.br/ 
b.3) construção de teatro.

Fases contempladas por indicações gerais: 1. Troca: deve-se estimular ações com acesso gratuito e oferta de financiamento através de editais (que de- vem estimular que as montagens sejam produzidas no município, estimulando a economia local); 2. Fruição e uso: contrapartida através de projeto-escola, debates junto às apresentações etc.

\begin{tabular}{|c|c|c|c|c|c|}
\hline \multicolumn{6}{|c|}{$\begin{array}{l}\text { EIXO 1: FRUIÇÃO E PRODUÇÃO ARTÍSTICA E CULTURAL } \\
\text { DESAFIO: FOMENTO ȦS ARTES CÊNICAS }\end{array}$} \\
\hline Ações propostas & \begin{tabular}{|l|} 
Tempo de \\
implementação
\end{tabular} & $\begin{array}{l}\text { Ciclo de } \\
\text { frequência }\end{array}$ & $\begin{array}{l}\text { Possiveis } \\
\text { parceiros }\end{array}$ & Resultados Esperados & $\begin{array}{l}\text { Formas de avaliação dos } \\
\text { resultados }\end{array}$ \\
\hline $\begin{array}{l}1.1 \\
\text { Oficinas de teatro e } \\
\text { de dança }\end{array}$ & Curto prazo & Anual & $\begin{array}{l}\text { - SM Educação } \\
\text { (integração } \\
\text { curricular); } \\
\text { - grupos locais }\end{array}$ & $\begin{array}{l}4 \text { oficinas semanais: } \\
\text { a) teatro; } \\
\text { b) dança; } \\
\text { c) cenografia; } \\
\text { d) figurino maquilagem }\end{array}$ & $\begin{array}{l}\text { relatórios dos oficineiros; } \\
\text {. acompanhamento dos } \\
\text { egressos. }\end{array}$ \\
\hline $\begin{array}{l}1.2 \text { Workshops com } \\
\text { grupos artísticos } \\
\text { (locais e externos) }\end{array}$ & Curto prazo & Bienal & - MinC & $\begin{array}{l}3 \text { workshops ( } 1 \text { a cada } 6 \\
\text { meses): teatro, dança e circo }\end{array}$ & $\begin{array}{l}\text { lista de presença; } \\
\text {. atratividade de grupos externos. }\end{array}$ \\
\hline $\begin{array}{l}1.3 \text { Residências } \\
\text { artísticas }\end{array}$ & Médio prazo & $\begin{array}{l}\text { Chamada anual ( } 3 \\
\text { meses cada) }\end{array}$ & $\begin{array}{l}\text { - FUNANRTE; } \\
\text { - Universidades }\end{array}$ & $\begin{array}{l}5 \text { residências por ano e } 5 \\
\text { apresentações públicas de } \\
\text { resultados/ano }\end{array}$ & $\begin{array}{l}\text { - demanda pelo programa; } \\
\text { - grau de satisfação do público } \\
\text { expectador; } \\
\text { - reverberação em espetáculos }\end{array}$ \\
\hline $\begin{array}{l}\text { 1.4 Concursos e } \\
\text { festivais }\end{array}$ & Médio prazo & $\begin{array}{l}\text { Bienal, sg. } \\
\text { modalidades } \\
\text { (dramaturgia; } \\
\text { esquetes etc.) }\end{array}$ & $\begin{array}{l}\text { - Escolas; } \\
\text { - Agremiações e } \\
\text { referências locais } \\
\text { (júris) }\end{array}$ & $\begin{array}{l}\text { Apresentações públicas de } \\
\text { poesias e esquetes. } \\
\text { Publicação de poesias e } \\
\text { contos. }\end{array}$ & $\begin{array}{l}\text { - públicos participantes } \\
\text { - procura pelas publicações nas } \\
\text { bibliotecas }\end{array}$ \\
\hline $\begin{array}{l}1.5 \\
\text { Editais de } \\
\text { circulação de } \\
\text { espetáculos } \\
\end{array}$ & Médio prazo & Bienal & $\begin{array}{l}\text { - Municípios da } \\
\text { região } \\
\text { - SEC-RJ } \\
\text { - FUNARTE }\end{array}$ & "x" espetáculos apresentados & $\begin{array}{l}\text { - públicos } \\
\text { - municípios envolvidos } \\
\text { - grupos participantes e } \\
\text { concorrentes }\end{array}$ \\
\hline $\begin{array}{l}1.6 \text { Construção de } \\
\text { teatro }\end{array}$ & Longo prazo & Único & $\begin{array}{l}\text { - SM Obras; } \\
\text { - Empresas; } \\
\text { - MinC e Min. } \\
\text { Turismo } \\
\end{array}$ & $\begin{array}{l}\text { Teatro capaz de abrigar } \\
\text { espetáculos cênicos e } \\
\text { multimídias }\end{array}$ & $\begin{array}{l}\text { - atratividade do equipamento } \\
\text { - capacidade de absorção das } \\
\text { produções locais }\end{array}$ \\
\hline
\end{tabular}

\section{Exemplo exploratório 2:}

Segundo levantamentos sobre 0 município de CABO FRIO, o I Fórum Municipal de Cultura (2009) elencou o fortalecimento do movimento de Cultura Negra como proposta.

\section{Considerando como DESAFIO,} dentro do eixo MANIFESTAÇÕES CULTURAIS POPULARES, o fomento às expressões étnicas de matriz afrobrasileira, podemos então buscar elencar um conjunto de ações (todas presentes no referido documento) para enfrentar tal Desafio.

Levando em conta as fases do circuito ou sistema de produção cultural, temos: Criação / Produção: a.1) apoiar oficinas comunitárias em territórios quilombolas e demais áreas do município, com temáticas focadas nas expressões culturais afrobrasileiras;

a.2) apoiar e estimular a ampliação das ações dos Quilombos, através de editais específicos (ou de eixo próprio no PROED - Programa de Editais)

Distribuição e divulgação:

b.1) apoiar com infraestrutura a promoção de feiras de produtos em eventos e festivais; cia Negra;

b.2) instituir Semana de ConsciênCultural;

b.3) criar Festival da Diversidade

b.4) criar Centro de Referência de Cultura Afrobrasileira. 
Fases contempladas por indicações gerais: 1. Troca: deve-se estimular ações com acesso gratuito e oferta de fi- nanciamento através de editais; 2 . Fruição e uso: estimular debates a diversidade cultural e étnica nas escolas.

\begin{tabular}{|c|c|c|c|c|c|}
\hline \multicolumn{6}{|c|}{\begin{tabular}{|c|} 
EIXO 2: MANIFESTAÇÕES CULTURAIS POPULARES \\
DESAFIO: AMPLIAÇÃO DE AÇÕES DE CULTURA NEGRA
\end{tabular}} \\
\hline Ações propostas & \begin{tabular}{|l|} 
Tempo de \\
implementação
\end{tabular} & $\begin{array}{l}\text { Ciclo de } \\
\text { frequência }\end{array}$ & Possíveis parceiros & Resultados Esperados & $\begin{array}{l}\text { Formas de avaliação dos } \\
\text { resultados }\end{array}$ \\
\hline $\begin{array}{l}1.1 \\
\text { Oficinas de cultura afro }\end{array}$ & Curto prazo & Anual & $\begin{array}{l}\text { - SM Educação } \\
\text { (implementação da Lei } \\
\text { 10.639); } \\
\text { - mestres griôs } \\
\end{array}$ & Oficinas semanais (a definir) & $\begin{array}{l}\text { relatórios dos oficineiros; } \\
\text { quantificação das ofertas em } \\
\text { eventos e feiras. }\end{array}$ \\
\hline \begin{tabular}{|l|}
1.2 \\
Editais para fomento das \\
ações dos quilombos
\end{tabular} & Curto prazo & Bienal & $\begin{array}{l}\text { - Secretaria de Promoção } \\
\text { da Igualdade Racial } \\
\text { (SEPIR). }\end{array}$ & Programa bienal de editais & $\begin{array}{l}\text { relatórios dos grupos apoiados; } \\
\text { avaliação dalatratividade } \\
\text { territorial gerada. }\end{array}$ \\
\hline $\begin{array}{l}1.3 \\
\text { Promoção de Feiras de } \\
\text { produtos }\end{array}$ & Curto prazo & Diversa & $\begin{array}{l}\text { - Territórios quilombolas e } \\
\text { outros grupos locais }\end{array}$ & \begin{tabular}{|l|} 
Realização de feiras com \\
participação de produtos de \\
grupos afrobrasileiros
\end{tabular} & $\begin{array}{l}\text { - procura pela participação em } \\
\text { feiras }\end{array}$ \\
\hline \begin{tabular}{|l|l}
1.4 \\
Implementação da \\
Semana de Consciência \\
Negra
\end{tabular} & Curto prazo & Anual & $\begin{array}{l}\text { - escolas } \\
\text { - quilombos } \\
\text { - grupos diversos }\end{array}$ & $\begin{array}{l}\text { Realização anual das } \\
\text { Semanas }\end{array}$ & $\begin{array}{l}\text { - envolvimento dos grupos locais } \\
\text { com os eventos }\end{array}$ \\
\hline $\begin{array}{l}1.5 \\
\text { Criação de Festival da } \\
\text { Diversidade Cultural }\end{array}$ & Curto prazo & Anual & $\begin{array}{l}\text { - escolas municipais } \\
\text { - ONGs }\end{array}$ & $\begin{array}{l}\text { Realização anual dos } \\
\text { Festivais }\end{array}$ & $\begin{array}{l}\text { - envolvimento dos grupos com a } \\
\text { realização de festivais } \\
\text { - capacidade geral de } \\
\text { atratividade dos eventos }\end{array}$ \\
\hline $\begin{array}{l}1.6 \text { - Criação de Centro } \\
\text { de Referência de Cultura } \\
\text { Negra }\end{array}$ & Médio prazo & Único & $\begin{array}{l}\text { - Ministério do Turismo } \\
\text { - MinC }\end{array}$ & Criação do Centro & - relatórios de presença \\
\hline
\end{tabular}

\section{Exemplo exploratório 3:}

Segundo levantamentos da realidade e demandas do município de ANGRA DOS REIS apontadas na $8^{\text {a }}$ Conferência Municipal de Cultura (2013), destacou-se como DESAFIO, dentro do eixo TURISMO CULTURAL, PATRIMÔNIO AMBIENTAL E CONSTRUÍDO, ações de preservação e valorização do patrimônio histórico-cultural e ambiental. Levando em conta as fases do circuito ou sistema de produção cultural, temos: Criação / Produção:

a.1) desenvolver oficinas regulares de educação ambiental e patrimonial nas escolas públicas;

a.2) implementar editais para pesquisas históricas, e publicações;

a.3) realizar inventário do patrimônio arquitetônico (formal e afetivo);

a.4) ações de arqueologia.

Distribuição e divulgação: b.1) contratação de técnicos em conservação, manutenção e restauração do patrimônio histórico;

b.2) implementar programa de visitas guiadas aos bens arquitetônicos e ambientais;

b.3) criação de arquivo público, abrigando também o acervo do Museu de Artes Sacras;

b.4) criação e fiscalização de leis de patrimônio (tombamento de sítios históricos, conjuntos arquitetônicos e paisagens culturais e naturais);

b.5) criação do Conselho de Patrimônio, com participação da sociedade civil;

b.6) criação de Escritório do Patrimônio Ambiental, localizado em Ilha Grande.

Fases contempladas por indicações gerais: 1. Troca: deve-se estimular ações com acesso gratuito e também subsidiadas por instituições localizadas em bens históricos; 2. Fruição e uso: estimular debates, visitas e publicações. 


\begin{tabular}{|c|c|c|c|c|c|}
\hline \multicolumn{6}{|c|}{$\begin{array}{l}\text { EIXO 3: TURISMO CULTURAL, PATRIMÔNIO AMBIENTAL E CONSTRUÍDO } \\
\text { DESAFIO: PRESERVAÇÃO E VALORIZAÇÃO DO PATRIMÔNIO HISTÓRICO-CULTURAL E AMBIENTAL }\end{array}$} \\
\hline Ações propostas & \begin{tabular}{|l|} 
Tempo de \\
implementação
\end{tabular} & \begin{tabular}{|l|} 
Ciclo de \\
frequência
\end{tabular} & \begin{tabular}{|l|} 
Possiveis \\
parceiros
\end{tabular} & Resultados Esperados & $\begin{array}{l}\text { Formas de avaliação dos } \\
\text { resultados }\end{array}$ \\
\hline $\begin{array}{l}1.1 \text { oficinas de educação ambiental } \\
\text { e patrimonial }\end{array}$ & Curto prazo & Bianual & $\begin{array}{l}\text { - SM Educação; } \\
\text { - instituições locais }\end{array}$ & Oficinas semestrais & $\begin{array}{l}\text { relatórios dos professores; } \\
\text { programa de redações } \\
\text { escolares }\end{array}$ \\
\hline $\begin{array}{l}1.2 \text { editais para pesquisas } \\
\text { históricas, e publicações }\end{array}$ & Médio prazo & Bienal & - SEC-RJ & Editais implantados & $\begin{array}{l}\text { - quantitativo de pesquisas } \\
\text { realizadas e editadas }\end{array}$ \\
\hline $\begin{array}{l}1.3 \text { inventário patrimônio } \\
\text { arquitetônico }\end{array}$ & Curto prazo & Único & universidades & Patrimônio inventariado & - bens inventariados \\
\hline 1.4 ações de arqueologia & Longo prazo & Diversas & - IPHAN & Sítios vitalizados & - ações desenvolvidas \\
\hline $\begin{array}{l}1.5 \text { contratação de técnicos } \\
\text { (conservação, manutenção e } \\
\text { restauração do patrimônio) }\end{array}$ & Curto prazo & Único & & Técnicos contratados & - quantitativo contratado \\
\hline $\begin{array}{l}1.6 \text { visitas guiadas aos bens } \\
\text { arquitetônicos e ambientais }\end{array}$ & Curto prazo & Mensal & - escolas públicas & $\begin{array}{l}\text { Visitas regulares aos } \\
\text { bens }\end{array}$ & $\begin{array}{l}\text { - número de visitas } \\
\text { realizadas }\end{array}$ \\
\hline 1.7 criação de arquivo público & Médio prazo & Único & $\begin{array}{l}\text { - Museu de Artes } \\
\text { Sacras }\end{array}$ & Arquivo Público & - quantitativo de visitação \\
\hline 1.8 criação de leis de patrimônio & Curto prazo & Único & $\begin{array}{l}\text { - câmara de } \\
\text { vereadores }\end{array}$ & $\begin{array}{l}\text { Leis criadas e } \\
\text { fiscalizadas }\end{array}$ & - preservação dos bens \\
\hline $\begin{array}{l}1.9 \text { criação do Conselho de } \\
\text { Patrimônio }\end{array}$ & Médio prazo & Único & $\begin{array}{l}\text { - câmara de } \\
\text { vereadores }\end{array}$ & $\begin{array}{l}\text { Conselho de Patrimônio } \\
\text { (participativo) }\end{array}$ & - ações do Conselho \\
\hline $\begin{array}{l}1.10 \text { criação de Escritório do } \\
\text { Patrimônio Ambiental }\end{array}$ & Longo prazo & Único & - IBAMA & $\begin{array}{l}\text { Escritório em llha } \\
\text { Grande }\end{array}$ & - ações do Escritório \\
\hline
\end{tabular}

Exemplo exploratório 4:

O eixo 4 - SOCIABILIDADE, COMUNICAÇÃO, PARTICIPAÇÃO SOCIAL E DESENVOLVIMENTO SÓCIO-ECONÔMICO SUSTENTÁVEL - se estrutura em ações muitas vezes transversais aos outros eixos. A criação de Conselhos com integrantes da sociedade, e ações de comunicação e interação entre governo e sociedade servem como ilustrações desta questão. Pensou-se, aqui, em uma breve frente de ação ligada ao município de ARRAIAL DO CABO, a saber: fortalecer a institucionalidade e gestão participativa das políticas municipais de cultura.

EIXO 4: SOCIABILIDADE, COMUNICAÇÃO, PARTICIPAÇÃO SOCIAL E DESENVOLVIMENTO SÓCIO-ECONÔMICO SUSTENTÁVEL DESAFIO: GESTÃO PARTICIPATIVA NA CULTURA

\begin{tabular}{|c|c|c|c|c|c|}
\hline Ações propostas & $\begin{array}{l}\text { Tempo de } \\
\text { implementação }\end{array}$ & $\begin{array}{l}\text { Ciclo de } \\
\text { frequência }\end{array}$ & Possíveis parceiros & Resultados Esperados & $\begin{array}{l}\text { Formas de avaliação } \\
\text { dos resultados }\end{array}$ \\
\hline $\begin{array}{l}1.1 \\
\text { Realizar } \\
\text { Conferências } \\
\text { Municipais de } \\
\text { Cultura }\end{array}$ & Curto prazo & Bienal & $\begin{array}{l}\text { - Entidades e grupos locais } \\
\text { - Escritório Regional do MinC }\end{array}$ & Conferências realizadas & $\begin{array}{l}\text { Participação da } \\
\text { sociedade e de } \\
\text { representantes } \\
\text { governamentais }\end{array}$ \\
\hline \begin{tabular}{l|}
1.2 \\
Criar e implantar o \\
Conselho Municipal \\
de Politica Cultural
\end{tabular} & Curto prazo & Único & $\begin{array}{l}\text { - Entidades municipais } \\
\text { - SM de Educ. } \\
\text { - SM de Meio Ambiente } \\
\text { - Câmara de Vereadores }\end{array}$ & Conselho instituido & $\begin{array}{l}\text { Reuniões do Conselho; } \\
\text { Participação dos } \\
\text { munícipes }\end{array}$ \\
\hline $\begin{array}{l}1.3 \\
\text { Instituir Fundo } \\
\text { Municipal de } \\
\text { Cultura }\end{array}$ & Curto prazo & Único & $\begin{array}{l}\text { - SM de Finanças } \\
\text { - Câmara de Vereadores }\end{array}$ & $\begin{array}{l}\text { Fundo regulamentado e } \\
\text { em desenvolvimento }\end{array}$ & $\begin{array}{l}\text { Editais realizados e } \\
\text { pagos }\end{array}$ \\
\hline
\end{tabular}

\section{À guisa de conclusão...}

O processo de dinamização junto aos municípios se revelou promissor.
Houve municípios que nunca tinham realizado conferência de cultura e cujos encontros de dinamização para alavancar o processo de construção do plano de 
cultura se mostraram potentes inclusive para instituir redes locais. Havia municípios que já tinham plano de cultura formulado, mas que perceberam na metodologia proposta uma possibilidade de se alcançar formulações mais concretas e realizáveis no tempo. Houve proposta para estruturar site para acompanhamento das ações do Plano em permanente processo de avaliação pela sociedade civil. Enfim... processos potentes em várias perspectivas.

Por outro lado, alguns gestores governamentais perceberam a necessidade de se pensar o planejamento de modo processual e compartilhado, pois as dificuldades de "escutas" e "presença” são realmente grandes... (mesmo quando bem intencionados, gestores não são oniscientes nem onipresentes; portanto o compartilhamento deve ser uma ação imanente aos processos de planejamento).

Pelo viés da universidade, as articulações técnicas possibilitaram maior aderência entre formulações teóricas e práticas sociais, saindo - cada vez mais - dos muros às vezes encastelados da academia...

Entretanto não se pode deixar de ponderar certas dificuldades que os processos participativos e compartilhados enfrentam. Por um lado, a fraca qualificação para a gestão cultural de muitos gestores de políticas públicas. Por outro, tímidas (por vezes, cabe reforçar) condições de autonomia e protagonismo de muitos agentes da sociedade; tais realidades geram condições muito desiguais de participação, como já apontou Ana Clarissa de Souza (2016) ao analisar as condições de participação de determinados conselheiros de cultura representantes da sociedade civil nos embates travados em reuniões nas quais representantes do executivo ocupam lugares privilegiados de fala e atuação.

\section{Referências}

BRUNNER, José Joaquín. La cultura como objeto de políticas. Santiago de Chile: FLACSO, 1985. Programa n. 74, out. 1985a.

BRUNNER, José Joaquín. A propósito de políticas culturales y democracia: um ejercicio formal. Santiago de Chile: FLACSO, 1985. Programa n. 254, ago. 1985b.

GARCÍA CANCLINI, Néstor. Políticas culturales y crisis de desarrollo: un balance latinoamericano. In: _ (org.) Políticas Culturales en América Latina. Buenos Aires: Grijalbo, 1987.

LIMA, Deborah Rebello; RODRIGUES, Luiz Augusto F. Ponto de cultura: novas tipologias de fomento a circuitos culturais - um exemplo brasileiro. Colonialismos, Pós colonialismos e lusofonias - Atas do IV Congresso Internacional em Estudos Culturais. Abril 2014, p. 852-859. Disponível em http://estudosculturais.com/ congressos/ivcongresso/wp-content/uploads/2014/04/ atas-PT-final.pdf>. Acesso em 30 abril 2014.

RODRIGUES, Luiz Augusto F. Gestão cultural e seus eixos temáticos. In: CURVELO, MariaAmélia [etal.] (org.). Políticas públicas de cultura do Estado do Rio de janeiro: 2007-2008. Rio de Janeiro: Uerj/Decult, 2009. p. 76-93

RODRIGUES, Luiz Augusto F.; CASTRO, Flávia Lages de. Cultua e ... Gestão Cultural. Rio e Janeiro: Lumen Juris, 2017.

RODRIGUES, Luiz Augusto F.; CASTRO, Flávia Lages de. Gestores culturais: proposta de categorização - nuances etnográficas. - Anais do XI RAM / Reunión de Antropologia del Mercosur. Montevideo, 2015. s/p. [Ainda não disponível on line]

RODRIGUES, Luiz Augusto F.; SILVEIRA, Marcelo S. Construção e gestão de políticas culturais compartilhadas. Anais do VII Seminário Internacional de Políticas Culturais. Rio de Janeiro: Fundação Casa de Rui Barbosa, 2016. 14p.

SOUZA, Ana Clarissa F. de. Democracia e compartilhamento da gestão pública de cultura: problematizando a participação social instrumentalizada do Sistema municipal de Cultura de Petrópolis-RJ. Dissertação de Mestrado em Cultura e Territorialidades. Niterói/RJ: Universidade Federal Fluminense, 2016.

SOUZA, Ana Clarissa F. de. Sistema Nacional de Cultura e Gestão Compartilhada: um estudo sobre o processo de construção do Sistema Municipal de Cultura de São Gonçalo - RJ. Rio de Jalo - RJ. Rio de Janeiro: Lumen Juris, 2015 